\title{
Enhanced co-culture and enrichment of human natural killer cells for the selective clearance of senescent cells
}

\author{
Kristie Kim¹, Tesfahun Dessale Admasu' ${ }^{1}$, Alexandra Stolzing ${ }^{1,2}$, Amit Sharma ${ }^{1}$ \\ ${ }^{1}$ SENS Research Foundation, Mountain View, CA 94041, USA \\ ${ }^{2}$ Loughborough University, Centre for Biological Engineering, Wolfson School of Electrical, Material and \\ Manufacturing Engineering, Loughborough, UK
}

Correspondence to: Amit Sharma; email: amit.sharma@sens.org

Keywords: aging, senescence, natural killer cells, NKCC, immune surveillance

Received: September 24, $2021 \quad$ Accepted: February 22, 2022

Published: March 4, 2022

Copyright: (C) 2022 Kim et al. This is an open access article distributed under the terms of the Creative Commons Attribution License (CC BY 3.0), which permits unrestricted use, distribution, and reproduction in any medium, provided the original author and source are credited.

\section{ABSTRACT}

In the context of aging and age-associated diseases, Natural Killer (NK) cells have been revealed as a key cell type responsible for the immune clearance of senescent cells. Subsequently, NK cell-based therapies have emerged as promising alternatives to drug-based therapeutic interventions for the prevention and treatment of age-related disease and debility. Given the promise of NK cell-mediated immunotherapies as a safe and effective treatment strategy, we outline an improved method by which primary NK cells can be efficiently enriched from human peripheral blood across multiple donors (ages 20-42 years old), with a practical protocol that reliably enhances both CD56 ${ }^{\mathrm{dim}}$ and CD56 ${ }^{\text {bright }}$ NK cells by 15 -fold and 3-fold, respectively. Importantly, we show that our co-culture protocol can be used as an easily adaptable tool to assess highly efficient and selective killing of senescent cells by primary NK cells enriched via our method using longer co-culture durations and a low target to effector ratio, which may be more physiological than has been achieved in previous literature.

\section{INTRODUCTION}

Advanced age is the greatest risk factor for most chronic diseases, with over $90 \%$ of adults aged 65 or older experiencing at least one chronic disease such as cancer, diabetes and cardiovascular disease [1]. Progressively increasing numbers of these adults are suffering from multimorbid age-related conditions [2]. Many aging phenotypes and pathologies, including diverse age-associated diseases and disorders, are causally linked to the accumulation of senescent cell burden with increasing age $[3,4]$. Senescent cells are characterized by an irreversible cell-cycle arrest of proliferation-competent cells, along with morphological and metabolic changes, altered gene expression, chromatin reorganization, and a complex proinflammatory senescence-associated secretory phenotype (SASP), which contributes to chronic inflammation and damage to surrounding cells and tissues $[4,5]$. Senescent cells are thought to be cleared by the immune system, but increasing age or disease severity allows senescent cells to escape the process of immunosurveillance and accumulate in older individuals [6]. The removal of senescent cells via drugs that selectively kill senescent cells ("senolytic" drugs) or genetic manipulation in transgenic mouse models can prevent or delay tissue dysfunction, improve age-related pathologies, and extend health span, suggesting that a reduced senescent cell burden in aging adults merits further study as a therapeutic target for the treatment and prevention of disease of aging $[7,8]$.

However, exploiting the ability of the innate immune system to surveille senescent cells has emerged as an alternative approach for their elimination [9]. Several lines of evidence show that Natural Killer (NK) cells play a vital role in the targeted elimination of senescent cells [9-11]. In fact, regulation of senescence burden by NK cells is not only considered essential for tissue homeostasis [12, 13], but also has been shown to be 
important for the regulation of pathological states such as tumor growth $[11,14]$. Moreover, impairment of NK cell function has been shown to accelerate aging in perforin-deficient mice due to the accumulation of senescent cells [15].

Although senescent cells are known to secrete chemokines as a part of the SASP to attract NK cells, they have also evolved strategies to evade clearance by NK cells [16]. For instance, senescent fibroblasts can escape immune surveillance by increasing expression of HLA-E, which upon interaction with NKG2A inhibits NK cell cytotoxicity [17]. Furthermore, senescent cells can shed MICA and MICB (ligands for the NK cellactivating receptor NKG2D), preventing the binding of NK cells to their targets $[18,19]$. Thus, whether through NK cell-based adoptive cell therapies or removal of NK cell inhibitory ligands, there is tremendous promise in modulating NK cells as an intervention against agerelated diseases [9].

However, an impediment to the development of NK cellbased senotherapeutic strategies is that although several publications have demonstrated the immune surveillance potential of NK cells towards senescent cells, the coculture strategies employed do not necessarily reflect physiological conditions. For instance, many studies demonstrating immune surveillance of senescent cells by NK cells used very high target to effector (T:E) ratios. It has been shown that most NK cell killing occurs through serial killing whereby a single NK cell can kill up to 10 targets [20]. Furthermore, a single IL-2-activated NK cell releases about a tenth of its total lytic granule reserve after 16 hours of co-culture [21, 22]. However, human YT cells (human NK cell line) have been used with T:E ratios as high as 1:20 to achieve modest cytotoxicity towards senescent IMR-90 cells [11, 23, 24]. Lannello et al. reportedly used $\mathrm{T}: \mathrm{E}$ ratios as high as 1:81 [25]. Interestingly, although Pereira et al. developed an autologous co-culture system with skin-derived primary human fibroblasts and NK cells, cytotoxicity towards senescent fibroblasts was low (10-20\%) even with a high $\mathrm{T}: \mathrm{E}$ ratio of 1:20 [17, 24, 25]. In addition, in most of these studies, co-culture experiments were performed for relatively short (2-6 hours) durations [11, 17, 23-25]. Finally, Interleukin-2 (IL-2) is a cytokine widely known to induce proliferation and activation of resting NK cells and is vital for their cytotoxic function both in cell culture and in vivo [26]. However, the concentration of IL-2 used to demonstrate the ability of NK cells to kill senescent cells varies substantially $[18,21,27,28]$.

In the present study, we demonstrate an easily adaptable and more physiological co-culture system in which we use freshly isolated peripheral NK cells cultured for 3 days with a relatively low concentration $(100 \mathrm{IU} / \mathrm{ml})$ of human recombinant Interleukin-2 (rIL-2). We have shown that even with different target cell types, NK cell donors, and methods of senescence induction, our coculture method is robust and reliable, consistently achieving two- to three-fold higher cytotoxicity of NK cells towards senescent cells compared to non-senescent cells at a co-culture duration of 16 hours and low 1:1 T:E ratio. Our protocols for NK cell isolation and enrichment and co-culture may more fully capture the interaction between senescent cells and NK cells than has been previously achieved. Importantly, this simple, robust protocol may serve as a platform for the development of novel NK cell-based senescent cell ablation strategies.

\section{RESULTS}

\section{Genotoxic stress-induced model of senescence}

Human fetal lung fibroblasts (IMR-90) cells were used as a cell culture model of cellular senescence. Robust induction of SA- $\beta$-gal activity was observed in $87 \%$ of doxorubicin-treated $(300 \mathrm{nM})$ cells, nine days after treatment whereas $1 \%$ of non-senescent control cells showed SA- $\beta$-gal activity (Figure 1A, 1B). In addition to doxorubicin treatment, additional models of senescence induction such as irradiation $(20 \mathrm{~Gy})$ and treatment with the mitochondria damaging agent, etoposide $(20 \mu \mathrm{M}, 48 \mathrm{~h})$ were tested. A statistically significant percentage of cells with increased SA- $\beta$-gal activity was observed in cells exposed to x-rays or etoposide ( $87 \%$ and $81 \%$, respectively) nine days after treatment compared to non-senescent control cells (1\%) (Supplementary Figure 1B, 1C).

The increase in SA- $\beta$-gal activity of doxorubicin-treated fibroblasts correlated with persistent DNA damage, as measured by immunofluorescence staining for $\gamma-\mathrm{H} 2 \mathrm{AX}$ (Figure 1C). The percentage of senescent cells with $>2 \gamma$ $\mathrm{H} 2 \mathrm{AX}$ foci per cell was eight-fold higher compared to that of non-senescent cells (Figure 1D). As expected, mRNA levels of cell cycle checkpoint markers p16 $6^{\mathrm{INK} 4 \mathrm{~A}}$ and $\mathrm{p} 21^{\mathrm{CIP} 1}$ were significantly elevated in senescent compared to non-senescent cells (Figure 1E). Loss of high mobility group box 1 (HMGB1), a highly conserved nuclear protein from senescent cells, is often used as a biomarker of senescence [29]. The loss of HMGB1 from the nucleus of our senescent fibroblasts was confirmed in doxorubicin-treated cells (Supplementary Figure 1A). Further, loss of Lamin B1 expression, another hallmark of senescence [30], was also observed in senescent compared to non-senescent cells (Figure 1F). Finally, increased mRNA levels of classical SASP factors IL-6, IL-8 and IL- $1 \alpha$ in senescent cells was confirmed by qRTPCR [31, 32] (Figure 1G). Collectively, these findings validated robust induction of a senescence phenotype in our cell culture model. 
A

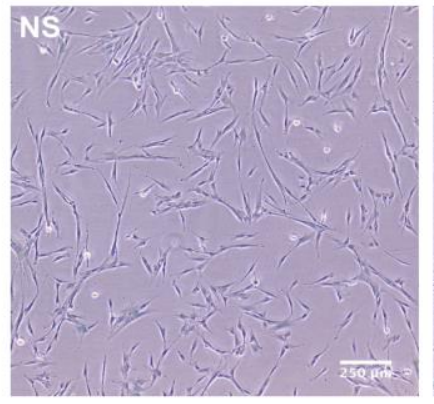

C
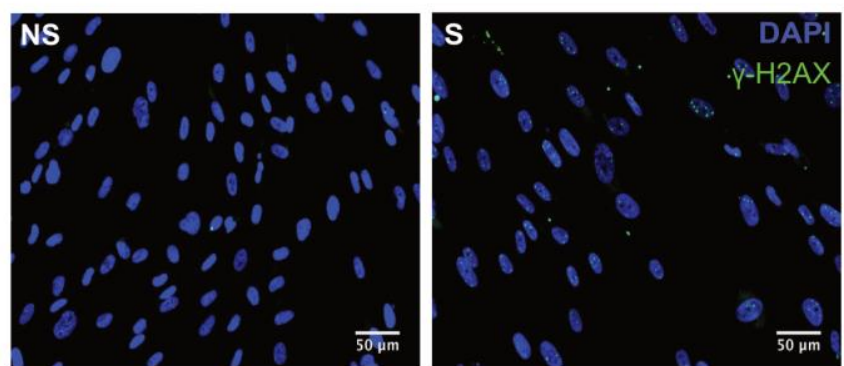

$E$

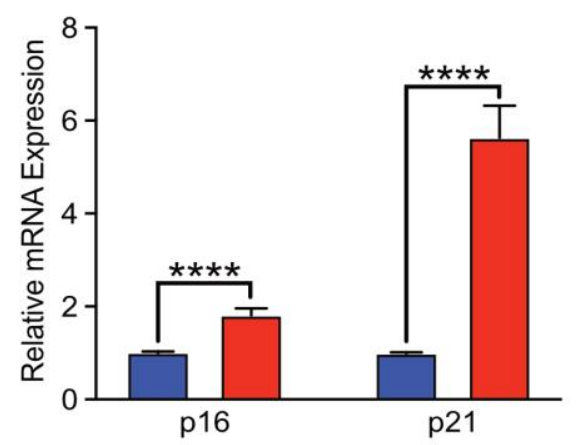

G

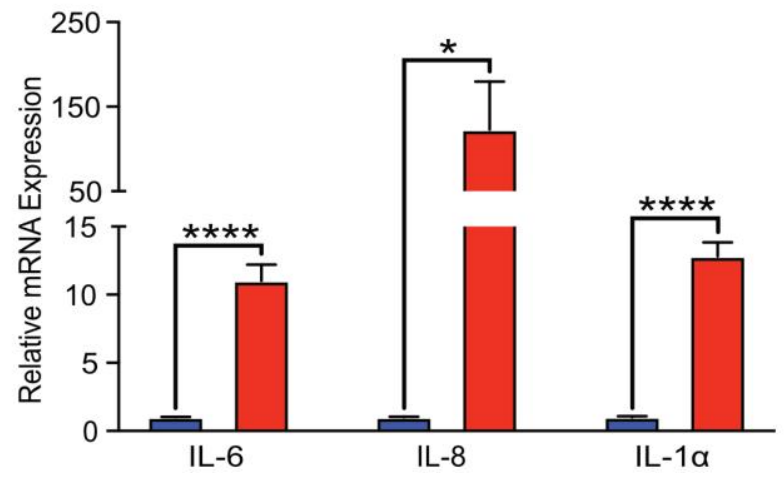

B
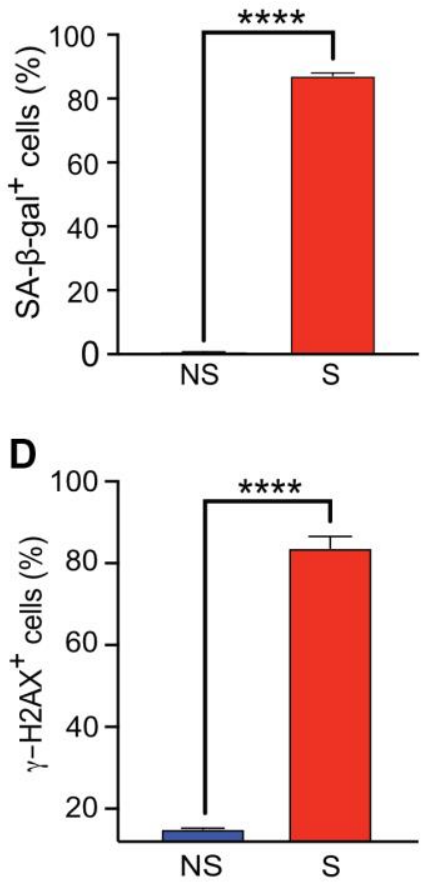

$\mathbf{F}$

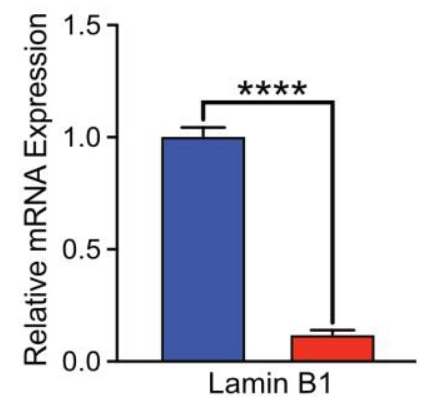

Figure 1. Senescent human fibroblasts express markers of senescence. IMR-90 fibroblasts were induced to senesce by doxorubicin $(300 \mathrm{nM}, 24 \mathrm{~h})$ and SA- $\beta$-Gal staining was performed on day 9 after doxorubicin treatment. (A) Representative images of SA- $\beta$-Gal stained senescent (S) and non-senescent (NS) cells. (B) Quantification of SA- $\beta$-gal-positive cells in NS and S IMR-90 cells. Four fields were quantified per well $(n=6)$ with a total of 7713 and 2666 cells counted for NS and S cells, respectively. (C) Immunofluorescence was performed to detect $\mathrm{Y}-\mathrm{H} 2 \mathrm{AX}$ in NS and S IMR-90 cells, 10 days after exposure to vehicle or doxorubicin, respectively. Representative images of NS and $\mathrm{S}$ cells stained for $\gamma-\mathrm{H} 2 \mathrm{AX}$ (green) and Hoechst (blue). (D) The percentage of cells with 3 or more $\psi-\mathrm{H} 2 \mathrm{AX}$ foci/cell $(\gamma-\mathrm{H} 2 \mathrm{AX}+$ cells) was scored from a total of $780 \mathrm{NS}$ and $387 \mathrm{~S}$ cells. The results are presented as mean \% of cells with 3 or more foci/cell. (E-G) mRNA levels of cell cycle regulators $p 16$ and $p 21$, Lamin B1, and various SASP factors, IL-6, IL-8, and IL- $1 \alpha$ assessed through Quantitative Realtime PCR in NS and S IMR90 cells $(n=3)$. All results are presented as a mean and error bars represent \pm SEM. Statistical analysis performed using unpaired $t$ test. ${ }^{*} p<$ $0.05, * * p<0.01$, and ${ }^{* * *} \mathrm{p}<0.001$ 


\section{Isolation and enrichment of NK cells}

Freshly drawn whole blood $(40 \mathrm{ml})$ was treated with RosetteSep human NK cell cocktail (Stem Cell Technologies, USA), which removes unwanted cells with Tetrameric Antibody Complexes that binds to white blood cells (except NK cells) and crosslinks them to red blood cells (RBCs). Following density gradient centrifugation, the NK cell population at the interface between the plasma and buoyant density medium was isolated. Freshly isolated NK cells were then incubated in RPMI media supplemented with $20 \% \mathrm{FBS}$ and $100 \mathrm{IU} / \mathrm{ml}$ rIL-2 for 72 hours for enrichment (Figure 2A).

The relative expression of CD56 and absence of CD3 are routinely used to identify human NK cells [33]. Low (CD56 $\left.{ }^{\mathrm{dim}}\right)$ and high (CD56 $\left.{ }^{\text {bright }}\right)$ CD56 expression levels define major subsets of NK cells [33]. CD56 ${ }^{\text {bright }}$ CD16- cells are considered immature NK cells that secrete interferon- $\gamma$ (IFN $\gamma$ ), whereas CD56 ${ }^{\mathrm{dim}} \mathrm{CD} 16^{+}$ NK cells are responsible for cytotoxicity [34]. Upon physical interaction with target cells, cytotoxic NK cells release perforin, granzymes (serine proteases), and other cytotoxic granules that kill their targets [35]. FACS analysis was performed to characterize NK cells freshly isolated from donors between the ages of 20-42 years. Results revealed a classic distribution of $\mathrm{CD}^{2} 6^{\text {bright }} \mathrm{CD} 16^{-}$and $\mathrm{CD}^{-\mathrm{dim}} \mathrm{CD}^{-} 6^{+} \mathrm{NK}$ cells, as evidenced by CD16 versus CD56 flow cytometry analysis in the scatter plots of fresh human Peripheral blood mononuclear cells (PBMCs) exemplified by one donor (after gating out CD3+ $\mathrm{T}$ cells as shown in Figure 2B-i and Supplementary Figure 2B). Specificity of antibodies was confirmed by Fluorescence minus one (FMO) control experiments with NK cell populations (Supplementary Figure 2C-i, 2C-ii). Interestingly, statistically significant enrichment of both sub-populations of NK cells was observed after culturing cells in media with rIL-2 for three days (Figure 2B-ii). This increase in the numbers of NK cell subtypes was consistent in NK cells isolated and enriched from multiple donors, with a fifteen-fold increase in the numbers of $\mathrm{CD} 56^{\mathrm{dim}} \mathrm{CD} 16^{+} \mathrm{NK}$ cells and approximately three-fold increase in the numbers of CD56 ${ }^{\text {bright }} \mathrm{CD} 16^{-} \mathrm{NK}$ cells (Figure $2 \mathrm{C}-\mathrm{i}, 2 \mathrm{C}$-ii).

\section{NK cell-mediated killing of senescent cells}

Senescent cells are known to secrete a variety of factors as part of the SASP that can attract NK cells and either activate or inhibit cytotoxic function $[9,14,36]$. To test whether senescent cells in our senescence model produced increased levels of these factors, we measured mRNA expression of multiple cytokines. A robust and statistically significant increase in the mRNA levels of
CCL5, CXCL9 and CXCL11, which are known chemoattractants for NK cells, was observed in senescent cells compared to non-senescent controls (Figure 3A). A modest increase in mRNA expression of CCL2, decreased expression of CXCL12, and non-significant difference in Chemerin compared to non-senescent cells was also observed (Supplementary Figure 2A).

Although the role of NK cells in targeting senescent cells has been previously demonstrated, the protocols used are quite variable and employ conditions that may not be as physiologically representative. Hence the cytotoxic potential of NK cells isolated and enriched with our protocol for the selective killing of senescent cells was determined by lactate dehydrogenase (LDH) release. Even at a T:E ratio of only 1:1, NK cells selectively eliminated senescent fibroblasts at a significantly higher (43\%) level compared to nonsenescent control cells (15\%) after 16 hours of coculture. In addition, twice (83\%) as many senescent fibroblasts were killed by NK cells when the T:E ratio was doubled to 1:2 compared to $41 \%$ in NS cells, and further increasing the T:E ratio to 1:3 killed nearly all senescent fibroblasts (93\%) compared to $51 \%$ in NS cells. However, at higher T:E ratios of $1: 2$ and 1:3, substantial killing of non-senescent cells was also observed (Figure 3B and Supplementary Figure 3A).

Recent publications have reported substantial variability among senescent cells based on mode of senescence induction and cell type [37]. Thus, whether NK cells enriched by our protocol can eliminate senescent cells induced to senesce by different stressors was investigated. NK cells killed $43-50 \%$ of senescent cells whether senescence was induced by doxorubicin (Figure 3C-i), irradiation (Figure 3C-ii) or etoposide (Figure 3Ciii) at statistically higher levels compared to cytotoxicity towards non-senescent cells (15\%). In addition, the senescence phenotype may also vary depending on cell type. Thus the efficacy of enriched NK cells in targeting senescent endothelial cells was also investigated [38]. Enriched and activated NK cells were observed to be effective at killing senescent endothelial cells at a threefold higher rate than NS endothelial cells (Figure 3C-iv) in a statistically significant manner.

Freezing primary NK cells often results in a decline in cytotoxicity [39]. However, our results showed that NK cells isolated and enriched with the protocol described above remained significantly more cytotoxic towards senescent cells compared to non-senescent cells following cryopreservation at a rate comparable to freshly isolated NK cells, as measured by LDH release after 16 hours of co-culture (Supplementary Figure 3B). Interestingly, when co-culture duration was extended to four days, the vast majority $(85-90 \%)$ of $\mathrm{NS}$ 
A

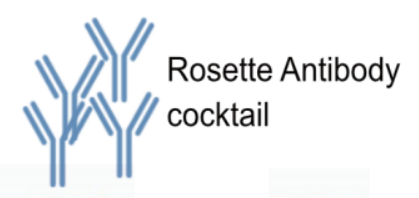
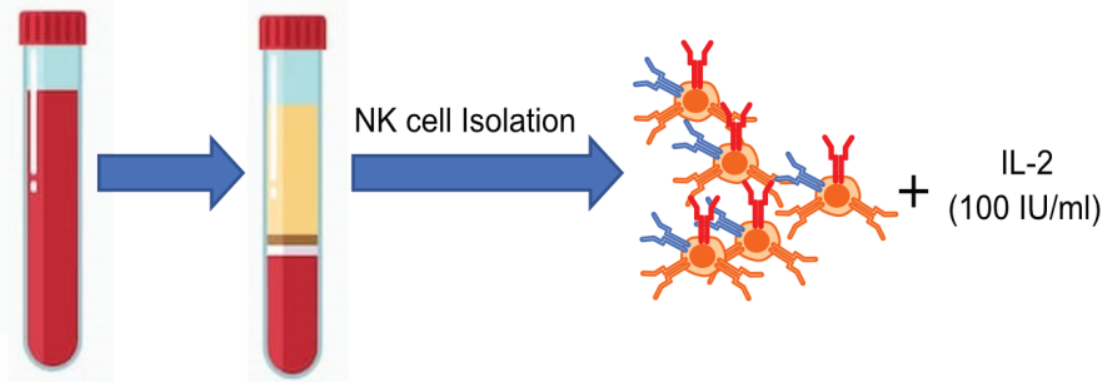

B-i

B-ii

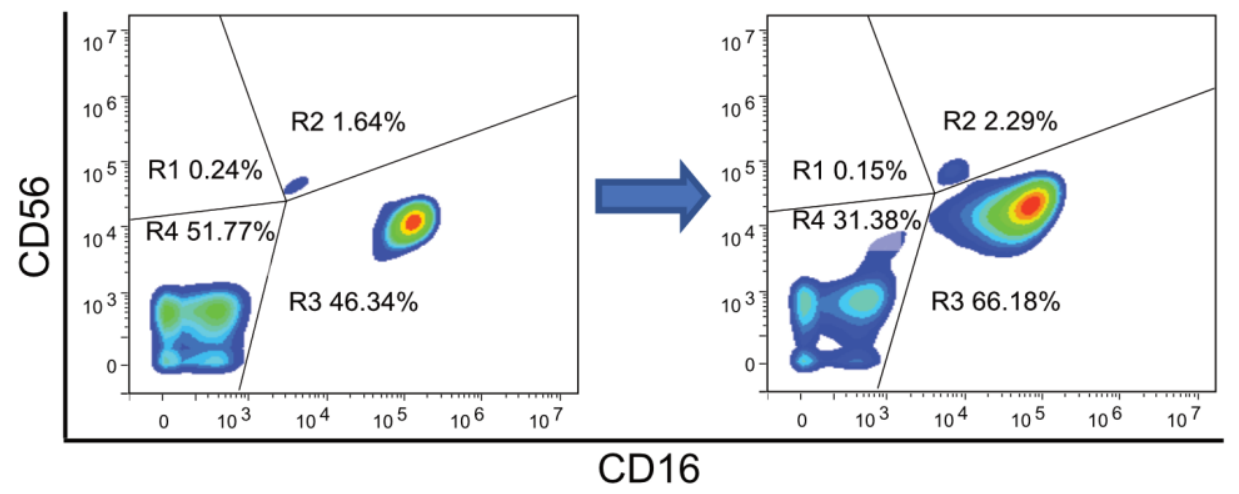

C-i

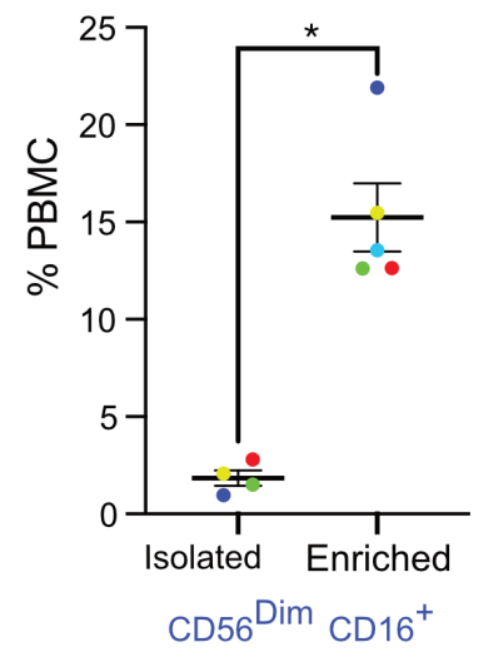

C-ii

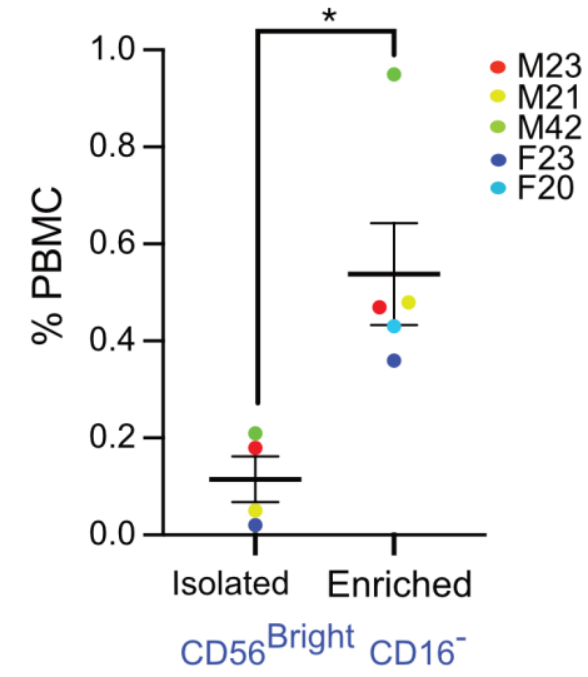

Figure 2. Isolation and enrichment strategy of primary NK cells from human PBMC. (A) Experimental design of the NK cell enrichment strategy. PBMCs were collected from multiple donors (ages 20-42 years old), and NK cells were isolated and enriched. (B) Flow cytometry analysis of CD56 and CD16 expression in NK cells before and after enrichment for a representative donor. (B-i) Before enrichment, $1.64 \%$ of NK cells $\left(0.18 \%\right.$ of PBMCs) were CD56 Bright CD16 and $46.34 \%$ of NK cells ( $2.8 \%$ of PBMCs) were CD56 ${ }^{\text {Dim }}$ CD16 ${ }^{+}$NK cells. (B-ii) After enrichment, $2.29 \%$ of NK cells ( $0.47 \%$ of PBMCs) were CD56 Bright CD16 and $66.18 \%$ of NK cells ( $12.6 \%$ of PBMCs) were CD56 Dim CD16 ${ }^{+}$NK cells. (C-i) Average percentage of CD56 ${ }^{\text {im }}$ CD16 ${ }^{+}$NK cell population in PBMCs from five donors. (C-ii) Average percentage of CD56 Bright CD16- NK cell population in PBMCs from five donors. Donor sex and age are indicated in the figure. Statistical analysis performed using paired test. ${ }^{*} \mathrm{p}<0.05, * * \mathrm{p}<0.01$, and $* * * \mathrm{p}<0.001$. 
A

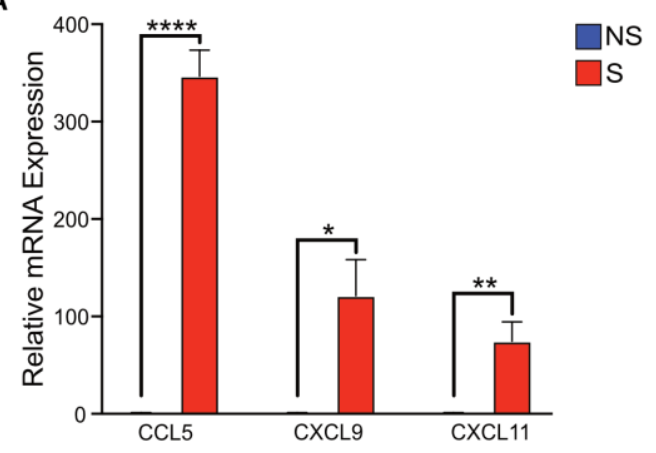

B

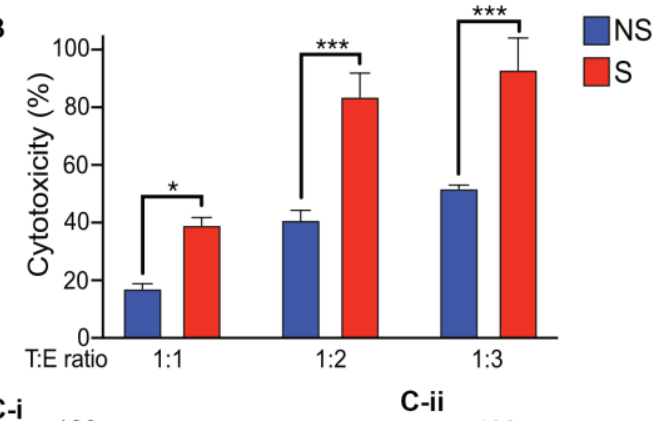

C-i
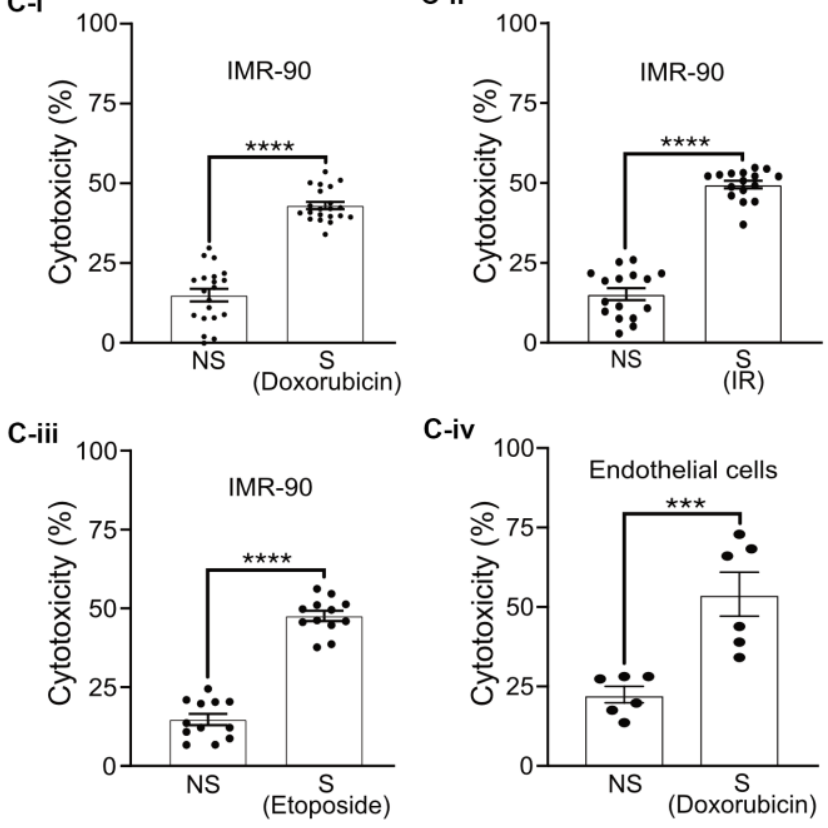

C-iv

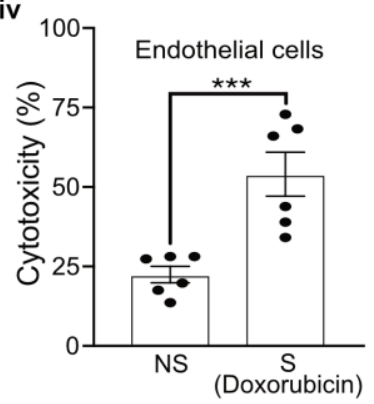

D

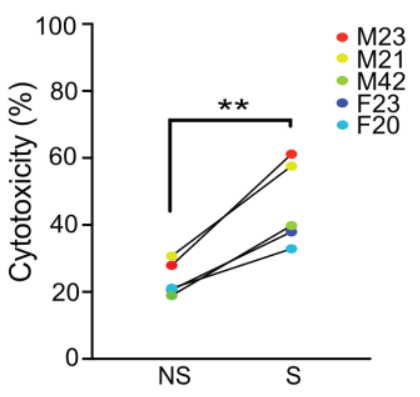

Figure 3. Activated primary NK cells selectively eliminate senescent cells. (A) Quantitative Realtime PCR was performed to detect the mRNA levels of CCL5, CXCL9, and CXCL11 in nonsenescent and senescent IMR-90 fibroblasts. The results are presented as mean fold change in NS compared to $S$ samples from two independent experiments performed in triplicate, and error bars represent \pm SEM. Statistical analysis performed using unpaired t test. ${ }^{*} p<0.05, * * p<0.01$, and $* * * p<0.001$. (B) NS or $S$ IMR-90 fibroblasts were co-incubated with NK cells for $16 \mathrm{~h}$ at $\mathrm{T}:$ E ratios of 1:1, 1:2 and 1:3 and cytotoxicity was evaluated by $\mathrm{LDH}$ release. The graphs show the mean and S.E. of \% LDH release. NS or S (C-i) doxorubicin-treated $(n=6),(\mathbf{C}$-ii) irradiated $(n=3)$ or (C-iii) etoposide-treated $(n=3)$ IMR-90 fibroblasts or (C-iv) doxorubicin-treated endothelial cells $(n=2)$ were overlayed with NK cells for 16 hours at T:E ratio of 1:1, and cytotoxicity was evaluated by LDH release. The results are plotted as mean \% cytotoxicity for NS and S cells with each experiment performed in at least triplicate. The graphs show mean \% LDH release. (D) NK cells isolated and enriched from three different individuals were co-cultured with NS or S IMR-90 cells at T:E ratio of 1:1 and cytotoxicity was evaluated by LDH release after 16 hours of coculture. Experiments were performed in triplicate and the results are plotted as mean \% cytotoxicity for NS and S. Donor sex and age are indicated in the figure. Statistical analysis performed using unpaired t test. ${ }^{*} p<0.05,{ }^{* *} p<0.01$, and $* * * p<0.001$.

cells survived, and only $10 \%$ and $30 \%$ of senescent cells were viable following co-culture with fresh or revived NK cells, respectively, as determined by Calcein AM (Supplementary Figure 3C).

Results from four days of co-culture were confirmed, demonstrating that only $6 \%$ and $17 \%$ of senescent cells survived following co-culture with NK cells even when senescence was induced by irradiation (Supplementary Figure 3D-i) or etoposide (Supplementary Figure 3Dii), respectively, whereas $85-100 \%$ of non-senescent cells survived following co-culture.

Finally, to test whether the cytotoxicity of primary NK cells prepared using our protocol was influenced by donor variability, senescent or non-senescent IMR-90 cells were co-cultured with NK cells isolated from multiple donors. A significantly higher cytotoxicity towards senescent compared to non-senescent cells was observed, as measured by LDH assay for each donor (Figure 3D). Furthermore, although the levels of Granzyme B released by activated NK cells correlated with overall cytotoxicity efficiency of individual NK cell donors, NK cells from each donor released similar amounts of Granzyme B upon co-culture with either senescent or non-senescent cells (Supplementary Figure 3E).

\section{DISCUSSION}

The involvement of senescent cells in aging and diseases of aging is well documented and has generated tremendous excitement amongst geroscientists as a potential therapeutic target for various age-related 
diseases. Several laboratories are attempting to develop therapeutic interventions to eliminate senescent cells using senolytic drug therapies. Although promising in animal models, unintended outcomes from senolytic interventions may be a potential concern [40-42]. A better understanding of the immune surveillance of senescent cells, and especially the key role of NK cells, offers a potential avenue to novel immunotherapies that can target senescent cells and expand healthspan.

NK cells are known to be one of the main effectors responsible for the immune surveillance of senescent cells. Hence, utilization of engineered NK cells as novel senotheraputics has emerged as an alternative to drugbased senolytic approaches. We investigated the viability of such an approach by demonstrating that our protocol is efficient in the isolation and enrichment of NK cells from PBMCs. Furthermore, this method can be used to assess the selective killing of senescent cells by NK cells in a practical and highly reproducible manner. Since senescence phenotype varies depending on the mode of senescence induction or cell type, we further showed that NK cells isolated and enriched with our protocol were also effective in killing senescent cells independent of cell origin or mode of senescence induction by doxorubicin, ionizing radiation or etoposide treatment.

To improve the efficiency of NK cell isolation, we isolated NK cells from PBMCs before expanding them in cell culture. The relative expression of CD56 and CD16 are commonly used to identify human NK cells [33]. CD56 ${ }^{\text {dim }}\left(\mathrm{CD} 16^{+}\right)$cells are the predominant NK cell population in circulation, whereas CD56 ${ }^{\text {bright }}$ (that are $\mathrm{CD} 16^{-}$) cells are considered a less mature stage of NK cells [33, 43, 44]. Cytotoxic function is thought to be performed by CD56 $6^{\text {dim }} \mathrm{NK}$ cells, while CD56 $6^{\text {bright }}$ NK cells are potent producers of cytokines such as IFN$\gamma$ and TNF- $\alpha[45,46]$. However, CD56 ${ }^{\text {bright }}$ NK cells are known to acquire cytotoxic function in the presence of cytokines such as IL-2 [47]. Consistent with previous reports, we observed a higher proportion of CD56 ${ }^{\mathrm{dim}}$ NK cells in freshly isolated PBMCs. Following isolation and enrichment, we observed expansion of both $\mathrm{CD} 56^{\text {dim }}$ and $\mathrm{CD} 56^{\text {bright }} \mathrm{NK}$ cell numbers by 15 and 3-fold, respectively, expressed as the mean of all five subjects at a relatively low rIL-2 concentration. IL2 is considered essential for the proliferation and function of NK cells. Although other cytokines such as IL-4, IL-7, and IL-12 have been used for NK cell enrichment, they have been reported to be overall less potent [48]. Of note, cryopreserved NK cells that have been untouched by cytokines in cell culture have been shown to have phenotype and cytotoxicity that resembles those of fresh cells; whether this is true for IL-2 activated and expanded NK cells has not been established [39]. Interestingly, our data reveal that cryopreservation of IL-2 activated NK cells isolated and enriched via our method have comparable cytotoxicity to freshly isolated NK cells.

Our results show that NK cells kill 40-50\% of senescent cells after $16 \mathrm{~h}$ at a $\mathrm{T}: \mathrm{E}$ ratio of 1:1, which is more efficient and under more physiological conditions than has been previously reported. For instance, others have reported T:E ratios as high as 1:81 and co-culture durations as short as $2 \mathrm{~h}$, which may not reflect physiological conditions [17, 18, 49]. A longer coculture can also be useful for capturing the mechanism of Natural Killer Cell Cytotoxicity (NKCC). For example, in addition to releasing lytic granules to kill their targets within a few hours after the start of coculture, NK cells are known to use additional mechanisms that require longer exposure to their targets, such as receptor-mediated apoptosis by expressing TRAIL or Fas ligand [50]. Thus, our improved co-culture strategy that employs more physiological T:E ratios (1:1) and longer co-culture durations (16 h or $4 \mathrm{~d}$ ) likely captures broader and important NK-senescent cell interactions that may be more informative for studying the immune surveillance of senescent cells.

To test the robustness of our NK cell enrichment protocol, we isolated NK cells from five healthy individuals between the ages of 20-42 years. Our results show two- to three-fold higher cytotoxicity toward senescent cells when compared to non-senescent controls. Interestingly, our data suggest that NK cells from younger males generally exhibited higher cytotoxicity than females and older donors. This observation warrants further investigation with a larger sample size. Several studies have characterized changes in the numbers of circulating NK cells as well as the distribution of NK cell subsets with increasing age [51, 52]. Additionally, an age-related increase has been observed in the numbers of dysfunctional or exhausted NK cells, which can be identified by decreased NK effector functions, reduced IFN- $\gamma$ secretion, and lower perforin and granzyme expression [53]. These observations suggest a potential decline in NKCC with age. Whether this general age-related decline in NKCC contributes to the age-dependent increase in senescence burden in older adults should be investigated.

A greater understanding of the mechanisms by which NK cells interact with senescent cells is needed to identify novel interventions for improving immune surveillance by NK cells. Senescent cells are known to secrete CCL2, CCL5, CXCL9 and CXCL11 along with other SASP factors [54-57]. To confirm that our senescent cells secreted elevated levels of cytokines and 
chemoattractants, we tested gene expression levels of CCL2, CCL5, CXCL9 and CXCL11. We observed substantially higher expression of these cytokines from senescent compared to non-senescent cells, which is important for the context of future in vivo studies as these chemokines are known to be main chemoattractants for NK cells [58-60]. However, we did not observe an increase in the expression of CXCL12 or chemerin, which were reported to be critical chemotactic factors for NK cell recruitment, by senescent fibroblasts. Chemerin/RARRES2 is commonly downregulated across several tumor types and often employed by tumor cells to escape immune clearance by tumor-infiltrating effector leukocytes [61]. Our data suggest that senescent cells may also employ similar strategies in vivo to escape immune clearance. Since ectopic expression of chemerin in the tumor microenvironment (TME) results in increased recruitment of NK cells [62], a similar strategy could be used for improving immune surveillance of senescent cells by NK cells.

In summary, we have developed a robust, easily adaptable cell co-culture model that involves isolation of human NK cells from peripheral blood, followed by enrichment in a relatively low IL-2 concentration. Our method for co-culturing NK cells with senescent cells may more fully capture the highly specific cytotoxicity towards senescent human fibroblasts and endothelial cells under more physiological conditions. We achieved significant cytotoxicity of NK cells towards senescent cells independent of donor variability using our enrichment strategy. Moreover, the specificity of primary NK cells towards senescent cells was further confirmed by a 4-day co-culture in which virtually all senescent cells were killed whereas viability of nonsenescent cells with NK cell effectors was visually indistinguishable from negative control cells untouched by effector cells. A deeper understanding of the interplay between senescent cells and NK cells is essential for the development of better therapeutic interventions, especially novel immunotherapies, for the treatment and prevention of age-associated diseases. The co-culture strategy presented here may serve as an important platform for the development of effective immunotherapies in the future that may involve the alteration and ultimately improvement of NK cell cytotoxicity towards senescent cells.

\section{MATERIALS AND METHODS}

\section{Cell culture}

Human primary NK cells were maintained at $37^{\circ} \mathrm{C}$ in humidified air containing $5 \% \mathrm{CO}_{2}$, and complete media containing RPMI-1640 medium (ATCC, USA; Cat\#30-
2001) supplemented with $20 \%$ Fetal Bovine Serum (FBS) (Millipore Sigma, USA; Cat\# F4135), 1X Penicillin-Streptomycin (Corning; Cat\# 30-001-CI), and $100 \mathrm{IU} / \mathrm{ml}$ human rIL-2 (recombinant Interleukin-2) (TECIN teceleukin; Bulk Ro 23-6019). IMR-90 primary lung fibroblasts (ATCC, USA: Cat\# CCL-186) were used at population doubling level (PDL) 30-47 and were cultured in an atmosphere with $5 \% \mathrm{CO}_{2}$ and $3 \% \mathrm{O}_{2}$ with complete media containing Dulbecco's Modified Eagle's Medium (DMEM) (Corning; Cat\# 10-013-CV) supplemented with 10\% Fetal Bovine Serum (FBS) (Millipore Sigma, US; Cat\# F4135) and 1X PenicillinStreptomycin (Corning; Cat\# 30-001-CI). Cumulative PDL was calculated using the following equation:

$$
\mathrm{PDL}=\frac{\log \mathrm{H}-\log \mathrm{S}}{\log 2}
$$

where $\mathrm{H}$ is the number of cells at harvest and $\mathrm{S}$ is the number of cells seeded. Primary human arterial endothelial cells purchased from Coriell Institute for medical research (AG10770) were maintained in promo cell basal medium MV2 (PromoCell; Cat\# C-22221) supplemented with Growth Medium MV 2 Supplement Pack (PromoCell; Cat\# C-39221) and assayed within 10 or less passages. Endothelial cells were maintained at $37^{\circ} \mathrm{C}$ in humidified air containing $5 \% \mathrm{CO}_{2}$.

\section{Senescence induction}

Senescence was induced in IMR-90 fibroblasts as described before with some modifications [63]. Cells were treated with $300 \mathrm{nM}$ doxorubicin hydrochloride (Millipore Sigma, USA; Cat\# 504042) in DMEM complete media for $24 \mathrm{~h}$ and maintained in culture as described for 10 days (d). Human endothelial cells were treated with $250 \mathrm{nM}$ doxorubicin in promo cell basal medium MV2 supplemented with Growth Medium MV 2 Supplement Pack for $24 \mathrm{~h}$ and maintained in culture as described [63]. For cells induced to senesce by irradiation, IMR-90 cells were treated with ionizing radiation (20 Gy X-ray). For cells induced to senesce by etoposide, fibroblasts were treated with $20 \mu \mathrm{M}$ of etoposide (Millipore Sigma, USA; Cat\# E1383) for $48 \mathrm{~h}$ and maintained in culture as described before.

\section{Senescence-associated B-galactosidase staining}

Senescence in IMR-90 cells was determined by senescence-associated B-galactosidase (SA-B-gal) activity, as reported [32], using the Senescence Detection Kit (BioVision; Cat\# K320), following the manufacturer's instructions. Fibroblasts were plated (5 x $10^{4}$ per well) 1 day before treatment in a 6-well cell culture plate (Greiner Bio-One; Cat\# 657160) with 2.5 $\mathrm{ml}$ of DMEM complete media per well. Non-senescent 
cells were plated $\left(1 \times 10^{5}\right)$ also in 6-well cell culture plates $1 \mathrm{~d}$ before staining. Staining was performed $9 \mathrm{~d}$ after doxorubicin treatment. During staining, cells were incubated for $48 \mathrm{~h}$ at $37^{\circ} \mathrm{C}$ in the absence of $\mathrm{CO}_{2}$, then visualized by bright-field microscopy and imaged. Percentage of SA-ß-gal-positive cells was counted manually.

\section{Real-time quantitative PCR}

Non-senescent IMR-90 fibroblasts were plated $\left(1 \times 10^{6}\right)$ in a T-75 cell culture flask (Cellstar; Cat\# 658170) with $10 \mathrm{ml}$ of DMEM complete media $2 \mathrm{~d}$ before cell pellet harvest. For senescent cells, fibroblasts were plated $(1 \mathrm{x}$ $\left.10^{6}\right) 1 \mathrm{~d}$ before doxorubicin treatment also in a T-75 cell culture flask, with $10 \mathrm{ml}$ of DMEM complete media. Senescent cells were pelleted $9 \mathrm{~d}$ after doxorubicin treatment. All cell pellets were stored at $-80^{\circ} \mathrm{C}$ before RNA isolation. Total RNA was isolated from cell pellets using Quick-RNA MiniPrep (Zymo Research; Cat\# R1055), following the manufacturer's protocol. 1 $\mu \mathrm{g}$ of total RNA per sample was reverse transcribed using PrimeScript RT Master Mix (Takara; Cat\# RR036B), and cDNA was analyzed by real-time qPCR using TaqMan Fast Advanced Master Mix (Applied Biosystems; Cat\# 4444557) (StepOnePlus ${ }^{\text {TM }}$ Real-Time PCR System). Gene expression analyses were performed with Applied Biosystems TaqMan Gene Expression single-tube assays. All reactions were performed in triplicate, and relative expression levels of each gene were normalized to actin. The relative expression of mRNA was determined using the comparative threshold $(\mathrm{Ct})$ method by normalizing target cDNA $\mathrm{Ct}$ values to that of actin.

\section{Immunofluorescence (IF)}

IMR-90 fibroblasts were plated for senescence induction $\left(2 \mathrm{x} \quad 10^{4} /\right.$ well $) 1 \mathrm{~d}$ before doxorubicin treatment in a black 96-well plate with square wells and a flat, clear bottom (Ibidi; Cat\# 89626), with 250 $\mu 1 /$ well of DMEM complete media. Non-senescent cells were plated $\left(2 \times 10^{\wedge} 5 /\right.$ well $) 2 \mathrm{~d}$ before staining. All immunostaining was performed $8 \mathrm{~d}$ after doxorubicin treatment. Cells were fixed with $200 \mu \mathrm{l} /$ well of $4 \%$ paraformaldehyde in 1X PBS (Thermo Scientific; Cat\# AAJ19943K2) for $15 \mathrm{~min}$ at room temperature, carefully rinsed with 1X PBS (Corning; Cat\# 21-031$\mathrm{CV}$ ), then permeabilized with $300 \mu \mathrm{l}$ per well of $0.5 \%$ Triton X-100 for $10 \mathrm{~min}$ at room temperature. Cells were rinsed once with $1 \mathrm{X}$ PBS and incubated with 250 $\mu \mathrm{l}$ per well of anti- $\gamma \mathrm{H} 2 \mathrm{AX}$ [p Ser139] (Novus Biologicals; Cat\# NB100-74435) and anti-HMGB1 (abcam; Cat\# ab18256) antibodies diluted in 5\% BSA (Research Products International; Cat\# A30075) in 1X PBS overnight at $4^{\circ} \mathrm{C}$. Subsequently, cells were washed
5 times with $1 X$ PBS and incubated with $250 \mu 1 /$ well of both Alexa Fluor 488 goat anti-mouse antibody (Invitrogen; Cat\# A11029) and Alexa Fluor 546 goat anti-rabbit antibody (Invitrogen; Cat\# A11010) along with Hoechst 33342, trihydrochloride, trihydrate (Invitrogen; Cat\# H3570) in 5\% BSA for $20 \mathrm{~min}$ at room temperature in the dark. Cells were washed 5 times with 1X PBS, then $200 \mu 1$ of 1X PBS was added to each well before images were acquired with Molecular Devices Image Express Micro (Molecular Devices, San Jose, CA, USA). Seven images were acquired per well, with five wells captured per condition (NS or S). Cells with $>2 \gamma-\mathrm{H} 2 \mathrm{AX}$ foci per nucleus were defined as senescent $(\mathrm{S})$.

\section{NK cell isolation and enrichment}

Blood samples were obtained from healthy donors $(\mathrm{n}=$ 5 , age range 20-42) in heparin coated vacutainers. All subjects provided informed written consent. Inclusion criteria for healthy individuals included those who did not take medication that could impact immunity (e.g., corticosteroids) and had no clinical indication of immunodeficiency. NK cells were isolated from freshly drawn human peripheral blood with RosetteSep Human NK Cell Enrichment Cocktail (Stemcell Technology, USA; Cat\# 15065) $3 \mathrm{~d}$ before co-culture with target cells. Rosette antibody cocktail was added to each blood sample $(30 \mu \mathrm{l} / \mathrm{ml})$ to negatively select unwanted cells with Tetrameric Antibody Complexes that crosslink non-NK cells in human whole blood to red blood cells (RBCs). Blood samples were then incubated at room temperature for $40 \mathrm{~min}$, diluted with $1 \mathrm{X}$ PBS (Corning; Cat\# 21-031-CV), and combined with Lymphocyte Separation Medium (Corning; Cat\# 25-072-CI) followed by density gradient centrifugation, according to the manufacturer's instructions. Once isolated, NK cells were enriched and activated for 3 days in RPMI complete media with $100 \mathrm{IU} / \mathrm{ml}$ human rIL-2 (recombinant Interleukin-2) (R and D Systems; Cat\# 8879-IL-010) before co-culturing with senescent or non-senescent IMR-90 fibroblasts.

\section{NK cell characterization}

Peripheral blood mononuclear cells (PBMCs) or enriched NK cells were resuspended to a concentration of $1 \times 10^{6}$ cells $/ \mathrm{ml}$ in FACS buffer (1\% BSA in PBS $+0.01 \%$ sodium azide) and aliquoted. Cells were washed 2 times with 1X PBS and resuspended in FACS buffer. Cells were then incubated with APC-conjugated anti-human CD3 antibody (Miltenyi Biotec; Cat\# 130-113-135), PEconjugated anti-human CD16 antibody (Miltenyi Biotec; Cat\# 130-113-393) and FITC-conjugated anti-human CD56 antibody (Miltenyi Biotec; Cat\# 130-114-549) for $30 \mathrm{~min}$ at room temperature in the dark. Then, cells were 
washed 3 times with FACS buffer and resuspended in $200 \mu \mathrm{l}$ of FACS buffer. Finally, 500,000 events were collected by flow cytometer (DB Accuri C6). Cell viability was determined by PI staining and live cells were gated for downstream analysis. Lymphocytes were gated based on forward and side scatter followed by gating to CD3- cells as NK cells. Finally, percentages of CD56dim CD16+ and CD56bright CD16- NK cells were determined across multiple donors. The data were acquired for at least 100,000 cells/sample. Data were analyzed using Flowlogic software (Miltenyi Biotech, Germany).

\section{Method for co-culture of NK effector cells with IMR-90 target cells}

IMR-90 fibroblasts were seeded ( $2 \times 104$ well) onto 24 well cell culture plates (Greiner Bio-One; Cat\# 662160) with a $1 \mathrm{ml}$ volume of DMEM complete media $10 \mathrm{~d}$ before co-culture. Senescence was induced $9 \mathrm{~d}$ before co-culture by treatment with $300 \mathrm{nM}$ of doxorubicin for $24 \mathrm{~h}$. Media was replaced with fresh DMEM complete media every 2-3 d. $3 \mathrm{~d}$ before co-culture with NK cells, non-senescent IMR-90 fibroblasts were seeded (1 x $10^{\wedge} 4$ per well) onto 24 -well cell culture plates (Greiner Bio-One; Cat\# 662160) with $1 \mathrm{ml}$ DMEM complete media. $24 \mathrm{~h}$ before co-culture, each well was replaced with $250 \mu \mathrm{l} /$ well of DMEM complete media to allow for SASP accumulation from senescent cells. Additional wells containing no target cells were included for media only and NK cell spontaneous lactate dehydrogenase (LDH) release controls. At the start of co-culture, NK cells were added in $250 \mu \mathrm{l} /$ well of RPMI complete media at a target to effector (T:E) ratio of 1:1 for a total of volume of $500 \mu \mathrm{l}$ per well. Co-cultures were incubated at $37^{\circ} \mathrm{C}$ in humidified air containing 5\% $\mathrm{CO}_{2}$ for $16 \mathrm{~h}$. Bright-field images were taken after $16 \mathrm{~h}$ of co-culture for qualitative analysis of NK cell cytotoxicity.

\section{Cytotoxicity quantification}

Cytotoxicity was assessed after $16 \mathrm{~h}$ of co-culture incubation by quantifying LDH release levels in target cells using the CytoTox 96 Non-Radioactive Cytotoxicity Assay (Promega, Madison, WI, USA), which quantitatively measures LDH released upon cell lysis. Baseline expression of LDH in culture medium alone, medium with target cells only, and medium with NK cells only were used as negative controls. Fibroblasts treated with $0.2 \%$ Triton $\mathrm{X}-100$ served as positive controls. Absorbance was recorded at $490 \mathrm{~nm}$ using SpectraMax i3 Multi-Mode Microplate Reader (Molecular Devices, San Jose, CA, USA). Average absorbance values for the culture medium background were subtracted from absorbance values for experimental and target cell spontaneous LDH release. The data are presented as an index calculated as:

$$
\begin{aligned}
& \text { Experimental - Effector } \\
& \text { Spontaneous } \\
& \% \text { Cytotoxicity }=\frac{- \text { Target Spontaneous }}{\text { Positive control }} \times 100 \\
& \text {-Target Spontaneous }
\end{aligned}
$$

\section{Granzyme B release assay}

Secretion of granzyme B was determined in the supernatant of NK/IMR90-cell co-cultures after $16 \mathrm{~h}$. Coculture plates were subject to centrifugation at $400 \mathrm{xg}$ for $5 \mathrm{~min}$. Supernatant was collected and used to measure human granzyme B by enzyme-linked immunosorbent assay (ELISA) kit ( $\mathrm{R}$ and D Systems; DY2906-05), according to the manufacturer's instructions.

\section{Cell viability assay with Calcein AM}

Fibroblasts were carefully rinsed 4 times with $1 \mathrm{X}$ PBS $(1 \mathrm{ml} /$ well) to wash away effector (NK cells) and dead detached cells. Target cells were stained with $1 \mu \mathrm{M}$ of Calcein AM (diluted from a $4 \mathrm{mM}$ stock solution in dimethyl sulfoxide (DMSO), Invitrogen; Cat\# C3099) in no-serum DMEM for $30 \mathrm{~min}$ in a $37^{\circ} \mathrm{C}$ incubator at a volume of $250 \mu \mathrm{l} /$ well. Following incubation, fluorescence values were recorded at $530 \mathrm{~nm}$ using SpectraMax i3 Multi-Mode Microplate Reader (Molecular Devices, San Jose, CA, USA).

\section{AUTHOR CONTRIBUTIONS}

KK designed and performed experiments, analyzed data, and wrote the manuscript. TDA analyzed results and helped edit the manuscript. AS helped edit the manuscript. AS designed experiments, supervised research, and helped to prepare the manuscript.

\section{ACKNOWLEDGMENTS}

We thank postbaccalaureate fellow Ms. Gina Zhu for assisting with some initial experiments with endothelial cells.

\section{CONFLICTS OF INTEREST}

The authors declare that they have no conflicts of interest.

\section{FUNDING}

This work was funded by grants from National Academy of Medicine's (NAM) Healthy Longevity 
Catalyst Award \# 2000011734. The study's funders had no role in the study design, data collection, analysis, interpretation and report writing. The corresponding author had full access to all the data and had final responsibility for the decision to submit for publication.

\section{REFERENCES}

1. Rae MJ, Butler RN, Campisi J, de Grey AD, Finch $C E$, Gough M, Martin GM, Vijg J, Perrott KM, Logan BJ. The demographic and biomedical case for late-life interventions in aging. Sci Transl Med. 2010; 2:40 cm21. https://doi.org/10.1126/scitranslmed.3000822 PMID:20630854

2. Espeland MA, Crimmins EM, Grossardt BR, Crandall JP, Gelfond JA, Harris TB, Kritchevsky SB, Manson JE, Robinson JG, Rocca WA, Temprosa M, Thomas F, Wallace R, Barzilai N, and Multimorbidity Clinical Trials Consortium. Clinical Trials Targeting Aging and AgeRelated Multimorbidity. J Gerontol A Biol Sci Med Sci. 2017; 72:355-61.

https://doi.org/10.1093/gerona/glw220

PMID:28364543

3. Baker DJ, Wijshake T, Tchkonia T, LeBrasseur NK, Childs BG, van de Sluis B, Kirkland JL, van Deursen JM. Clearance of p16Ink4a-positive senescent cells delays ageing-associated disorders. Nature. 2011; 479:232-6. https://doi.org/10.1038/nature10600 PMID:22048312

4. Ghosh K, Capell BC. The Senescence-Associated Secretory Phenotype: Critical Effector in Skin Cancer and Aging. J Invest Dermatol. 2016; 136:2133-9. https://doi.org/10.1016/j.jid.2016.06.621 PMID:27543988

5. Zhang ZD, Milman S, Lin JR, Wierbowski S, Yu H, Barzilai N, Gorbunova V, Ladiges WC, Niedernhofer LJ, Suh Y, Robbins PD, Vijg J. Genetics of extreme human longevity to guide drug discovery for healthy ageing. Nat Metab. 2020; 2:663-72.

https://doi.org/10.1038/s42255-020-0247-0 PMID:32719537

6. Prata LG, Ovsyannikova IG, Tchkonia T, Kirkland JL. Senescent cell clearance by the immune system: emerging therapeutic opportunities. Semin Immunol. 2018; 40:101275. https://doi.org/10.1016/j.smim.2019.04.003 PMID:31088710

7. Kirkland JL, Tchkonia T. Clinical strategies and animal models for developing senolytic agents. Exp Gerontol. 2015; 68:19-25.

https://doi.org/10.1016/j.exger.2014.10.012 PMID:25446976

8. Baker DJ, Childs BG, Durik M, Wijers ME, Sieben CJ, Zhong J, Saltness RA, Jeganathan KB, Verzosa GC,
Pezeshki A, Khazaie K, Miller JD, van Deursen JM. Naturally occurring p16(Ink4a)-positive cells shorten healthy lifespan. Nature. 2016; 530:184-9.

https://doi.org/10.1038/nature16932 PMID:26840489

9. Kale A, Sharma A, Stolzing A, Desprez PY, Campisi J. Role of immune cells in the removal of deleterious senescent cells. Immun Ageing. 2020; 17:16. https://doi.org/10.1186/s12979-020-00187-9 PMID: $\underline{2518575}$

10. Hoenicke L, Zender L. Immune surveillance of senescent cells-biological significance in cancer- and non-cancer pathologies. Carcinogenesis. 2012; 33:1123-6.

https://doi.org/10.1093/carcin/bgs124 PMID:22470164

11. Sagiv A, Biran A, Yon M, Simon J, Lowe SW, Krizhanovsky V. Granule exocytosis mediates immune surveillance of senescent cells. Oncogene. 2013; 32:1971-7.

https://doi.org/10.1038/onc.2012.206 PMID:22751116

12. Bataller R, Brenner DA. Liver fibrosis. J Clin Invest. 2005; 115:209-18.

https://doi.org/10.1172/JCI24282 PMID:15690074

13. Brighton PJ, Maruyama Y, Fishwick K, Vrljicak P, Tewary S, Fujihara R, Muter J, Lucas ES, Yamada T, Woods L, Lucciola R, Hou Lee Y, Takeda S, et al. Clearance of senescent decidual cells by uterine natural killer cells in cycling human endometrium. eLife. 2017; 6: e31274. https://doi.org/10.7554/eLife.31274 PMID:29227245

14. Xue W, Zender L, Miething C, Dickins RA, Hernando E, Krizhanovsky V, Cordon-Cardo C, Lowe SW. Senescence and tumour clearance is triggered by $\mathrm{p} 53$ restoration in murine liver carcinomas. Nature. 2007; 445:656-60. https://doi.org/10.1038/nature05529 PMID:17251933

15. Ovadya $Y$, Landsberger $T$, Leins $H$, Vadai $E$, Gal $H$, Biran A, Yosef R, Sagiv A, Agrawal A, Shapira A, Windheim J, Tsoory $M$, Schirmbeck $R$, et al. Impaired immune surveillance accelerates accumulation of senescent cells and aging. Nat Commun. 2018; 9:5435.

https://doi.org/10.1038/s41467-018-07825-3 PMID: $\underline{0575733}$

16. Bernardini G, Gismondi A, Santoni A. Chemokines and NK cells: regulators of development, trafficking and functions. Immunol Lett. 2012; 145:39-46.

https://doi.org/10.1016/j.imlet.2012.04.014 PMID:22698182

17. Pereira $\mathrm{Bl}$, Devine OP, Vukmanovic-Stejic $\mathrm{M}$, Chambers ES, Subramanian P, Patel N, Virasami A, Sebire NJ, Kinsler V, Valdovinos A, LeSaux CJ, Passos JF, Antoniou $A$, et al. Senescent cells evade immune clearance via HLA-E-mediated NK and $\mathrm{CD}^{+} \mathrm{T}$ cell inhibition. Nat Commun. 2019; 10:2387. 
https://doi.org/10.1038/s41467-019-10335-5 PMID:31160572

18. Muñoz DP, Yannone SM, Daemen A, Sun $Y$, VakarLopez F, Kawahara M, Freund AM, Rodier F, Wu JD, Desprez PY, Raulet DH, Nelson PS, van 't Veer L, et al. Targetable mechanisms driving immunoevasion of persistent senescent cells link chemotherapy-resistant cancer to aging. JCI Insight. 2019; 5: e124716.

https://doi.org/10.1172/jci.insight.124716

PMID:31184599

19. Zingoni A, Cecere F, Vulpis E, Fionda C, Molfetta R, Soriani A, Petrucci MT, Ricciardi MR, Fuerst $D$, Amendola MG, Mytilineos J, Cerboni C, Paolini R, et al. Genotoxic Stress Induces Senescence-Associated ADAM10-Dependent Release of NKG2D MIC Ligands in Multiple Myeloma Cells. J Immunol. 2015; 195:736-48. https://doi.org/10.4049/jimmunol.1402643 PMID:26071561

20. Choi PJ, Mitchison TJ. Imaging burst kinetics and spatial coordination during serial killing by single natural killer cells. Proc Natl Acad Sci USA. 2013; 110:6488-93.

https://doi.org/10.1073/pnas.1221312110

PMID:23576740

21. Vanherberghen B, Olofsson PE, Forslund E, SternbergSimon M, Khorshidi MA, Pacouret S, Guldevall K, Enqvist $\mathrm{M}$, Malmberg $\mathrm{KJ}$, Mehr $\mathrm{R}$, Önfelt $\mathrm{B}$. Classification of human natural killer cells based on migration behavior and cytotoxic response. Blood. 2013; 121:1326-34.

https://doi.org/10.1182/blood-2012-06-439851

PMID:23287857

22. Perera Molligoda Arachchige AS. Human NK cells: from development to effector functions. Innate Immun. 2021; 27:212-29.

https://doi.org/10.1177/17534259211001512 PMID:33761782

23. Krizhanovsky V, Yon M, Dickins RA, Hearn S, Simon J, Miething $C$, Yee $H$, Zender L, Lowe SW. Senescence of activated stellate cells limits liver fibrosis. Cell. 2008; 134:657-67.

https://doi.org/10.1016/j.cell.2008.06.049

PMID:18724938

24. Ruscetti $M$, Leibold J, Bott MJ, Fennell $M$, Kulick $A$, Salgado NR, Chen CC, Ho YJ, Sanchez-Rivera FJ, Feucht J, Baslan T, Tian S, Chen HA, et al. NK cell-mediated cytotoxicity contributes to tumor control by a cytostatic drug combination. Science. 2018; 362:1416-22.

https://doi.org/10.1126/science.aas9090

PMID:30573629

25. Iannello A, Thompson TW, Ardolino M, Lowe SW, Raulet $\mathrm{DH}$. p53-dependent chemokine production by senescent tumor cells supports NKG2D-dependent tumor elimination by natural killer cells. J Exp Med. 2013; 210:2057-69.

https://doi.org/10.1084/jem.20130783

PMID:24043758

26. Weil-Hillman G, Voss SD, Fisch $P$, Schell $K$, Hank JA, Sosman JA, Sugamura K, Sondel PM. Natural killer cells activated by interleukin 2 treatment in vivo respond to interleukin 2 primarily through the p75 receptor and maintain the p55 (TAC) negative phenotype. Cancer Res. 1990; 50:2683-91.

PMID: 1691679

27. Yin $X, X u X$, Zhao $Y$, Wang ZJ, Wang HY, Hu ZB. [Comparison of Several Optimization Schemes for the Induction and Expansion of Antibody-Mediated High Efficiency CIK (AMHE-CIK) In Vitro]. Zhongguo Shi Yan Xue Ye Xue Za Zhi. 2016; 24:191-6. https://doi.org/10.7534/j.issn.1009-2137.2016.01.036 PMID:26913419

28. Wei C, Wang W, Pang W, Meng M, Jiang L, Xue S, Xie Y, Li R, Hou Z. The CIK cells stimulated with combination of IL-2 and IL-15 provide an improved cytotoxic capacity against human lung adenocarcinoma. Tumour Biol. 2014; 35:1997-2007. https://doi.org/10.1007/s13277-013-1265-2 PMID:24104501

29. Davalos AR, Kawahara M, Malhotra GK, Schaum N, Huang J, Ved U, Beausejour CM, Coppe JP, Rodier F, Campisi J. p53-dependent release of Alarmin HMGB1 is a central mediator of senescent phenotypes. J Cell Biol. 2013; 201:613-29. https://doi.org/10.1083/icb.201206006 PMID:23649808

30. Freund A, Laberge RM, Demaria M, Campisi J. Lamin B1 loss is a senescence-associated biomarker. Mol Biol Cell. 2012; 23:2066-75. https://doi.org/10.1091/mbc.e11-10-0884 PMID:22496421

31. Coppé JP, Patil CK, Rodier F, Krtolica A, Beauséjour CM, Parrinello S, Hodgson JG, Chin K, Desprez PY, Campisi J. A human-like senescence-associated secretory phenotype is conserved in mouse cells dependent on physiological oxygen. PLoS One. 2010; 5:e9188.

https://doi.org/10.1371/journal.pone.0009188 PMID:20169192

32. Laberge RM, Sun $Y$, Orjalo AV, Patil CK, Freund A, Zhou L, Curran SC, Davalos AR, Wilson-Edell KA, Liu S, Limbad C, Demaria M, Li P, et al. MTOR regulates the pro-tumorigenic senescence-associated secretory phenotype by promoting IL1A translation. Nat Cell Biol. 2015; 17:1049-61. https://doi.org/10.1038/ncb3195 PMID:26147250 
33. Poli $A$, Michel $T$, Thérésine $M$, Andrès $E$, Hentges $F$, Zimmer J. CD56bright natural killer (NK) cells: an important NK cell subset. Immunology. 2009; 126:458-65.

https://doi.org/10.1111/j.1365-2567.2008.03027.x PMID:19278419

34. Moretta A, Bottino C, Vitale M, Pende D, Cantoni C, Mingari MC, Biassoni R, Moretta L. Activating receptors and coreceptors involved in human natural killer cell-mediated cytolysis. Annu Rev Immunol. 2001; 19:197-223.

https://doi.org/10.1146/annurev.immunol.19.1.197 PMID:11244035

35. Voskoboinik I, Smyth MJ, Trapani JA. Perforinmediated target-cell death and immune homeostasis. Nat Rev Immunol. 2006; 6:940-52. https://doi.org/10.1038/nri1983 PMID:17124515

36. Antonangeli F, Zingoni A, Soriani A, Santoni A. Senescent cells: living or dying is a matter of NK cells. J Leukoc Biol. 2019; 105:1275-83. https://doi.org/10.1002/JLB.MR0718-299R PMID: 30811627

37. Admasu TD, Rae $M$, Stolzing $A$. Dissecting primary and secondary senescence to enable new senotherapeutic strategies. Ageing Res Rev. 2021; 70:101412. https://doi.org/10.1016/i.arr.2021.101412 PMID:34302996

38. Salama R, Sadaie M, Hoare M, Narita M. Cellular senescence and its effector programs. Genes Dev. 2014; 28:99-114.

https://doi.org/10.1101/gad.235184.113

PMID:24449267

39. Cho D, Campana D. Expansion and activation of natural killer cells for cancer immunotherapy. Korean J Lab Med. 2009; 29:89-96.

https://doi.org/10.3343/kjlm.2009.29.2.89

PMID:19411773

40. Blagosklonny MV. Paradoxes of senolytics. Aging (Albany NY). 2018; 10:4289-93.

https://doi.org/10.18632/aging.101750

PMID:30594910

41. Kirkland JL, Tchkonia T. Cellular Senescence: A Translational Perspective. EBioMedicine. 2017; 21:21-8.

https://doi.org/10.1016/i.ebiom.2017.04.013 PMID:28416161

42. Zhu $Y$, Tchkonia $T$, Fuhrmann-Stroissnigg $H$, Dai HM, Ling YY, Stout MB, Pirtskhalava T, Giorgadze N, Johnson KO, Giles CB, Wren JD, Niedernhofer L, Robbins PD, Kirkland JL. Identification of a novel senolytic agent, navitoclax, targeting the $\mathrm{Bcl}-2$ family of anti-apoptotic factors. Aging Cell. 2016; 15:428-35. https://doi.org/10.1111/acel.12445

PMID:26711051

43. Carrega P, Bonaccorsi I, Di Carlo E, Morandi B, Paul P, Rizzello V, Cipollone G, Navarra G, Mingari MC, Moretta L, Ferlazzo G. CD56(bright)perforin(low) noncytotoxic human NK cells are abundant in both healthy and neoplastic solid tissues and recirculate to secondary lymphoid organs via afferent lymph. J Immunol. 2014; 192:3805-15.

https://doi.org/10.4049/jimmunol.1301889

PMID:24646734

44. Lugthart G, Melsen JE, Vervat C, van Ostaijen-Ten Dam MM, Corver WE, Roelen DL, van Bergen J, van Tol MJ, Lankester AC, Schilham MW. Human Lymphoid Tissues Harbor a Distinct CD69+CXCR6+ NK Cell Population. J Immunol. 2016; 197:78-84.

https://doi.org/10.4049/jimmunol.1502603 PMID:27226093

45. Michel T, Poli A, Cuapio A, Briquemont B, Iserentant G, Ollert M, Zimmer J. Human CD56bright NK Cells: an Update. J Immunol. 2016; 196:2923-31. https://doi.org/10.4049/jimmunol.1502570 PMID:26994304

46. Penack O, Gentilini C, Fischer L, Asemissen AM, Scheibenbogen C, Thiel E, Uharek L. CD56dimCD16neg cells are responsible for natural cytotoxicity against tumor targets. Leukemia. 2005; 19:835-40.

https://doi.org/10.1038/sj.leu.2403704 PMID: 15744340

47. Ferlazzo G, Thomas D, Lin SL, Goodman K, Morandi B, Muller WA, Moretta A, Münz C. The abundant NK cells in human secondary lymphoid tissues require activation to express killer cell Ig-like receptors and become cytolytic. J Immunol. 2004; 172:1455-62.

https://doi.org/10.4049/jimmunol.172.3.1455 PMID:14734722

48. Robertson MJ, Manley TJ, Donahue C, Levine H, Ritz J. Costimulatory signals are required for optimal proliferation of human natural killer cells. J Immunol. 1993; 150:1705-14.

PMID:679691

49. Sagiv A, Burton DG, Moshayev Z, Vadai E, Wensveen F, Ben-Dor S, Golani O, Polic B, Krizhanovsky V. NKG2D ligands mediate immunosurveillance of senescent cells. Aging (Albany NY). 2016; 8:328-44. https://doi.org/10.18632/aging.100897 PMID:26878797

50. Prager I, Watzl C. Mechanisms of natural killer cellmediated cellular cytotoxicity. J Leukoc Biol. 2019; 105:1319-29.

https://doi.org/10.1002/JLB.MR0718-269R PMID:31107565 
51. Almeida-Oliveira $A$, Smith-Carvalho $M$, Porto $L C$, Cardoso-Oliveira J, Ribeiro AS, Falcão RR, Abdelhay E, Bouzas LF, Thuler LC, Ornellas MH, Diamond HR. Agerelated changes in natural killer cell receptors from childhood through old age. Hum Immunol. 2011; 72:319-29.

https://doi.org/10.1016/j.humimm.2011.01.009

PMID:21262312

52. Chidrawar SM, Khan N, Chan YL, Nayak L, Moss PA. Ageing is associated with a decline in peripheral blood CD56bright NK cells. Immun Ageing. 2006; 3:10.

https://doi.org/10.1186/1742-4933-3-10

PMID:17134511

53. Bi J, Tian Z. NK Cell Exhaustion. Front Immunol. 2017; 8:760.

https://doi.org/10.3389/fimmu.2017.00760

PMID:28702032

54. Hwang HJ, Lee YR, Kang D, Lee HC, Seo HR, Ryu JK, Kim YN, Ko YG, Park HJ, Lee JS. Endothelial cells under therapy-induced senescence secrete CXCL11, which increases aggressiveness of breast cancer cells. Cancer Lett. 2020; 490:100-10.

https://doi.org/10.1016/i.canlet.2020.06.019

PMID:32659248

55. Yamane $M$, Sato $S$, Shimizu $E$, Shibata $S$, Hayano $M$, Yaguchi T, Kamijuku H, Ogawa M, Suzuki T, Mukai S, Shimmura S, Okano H, Takeuchi T, et al. Senescenceassociated secretory phenotype promotes chronic ocular graft-vs-host disease in mice and humans. FASEB J. 2020; 34:10778-800.

https://doi.org/10.1096/fj.201900218R

PMID:32619061

56. Shen L, Chen Y, Cheng J, Yuan S, Zhou S, Yan W, Liu J, Luo A, Wang S. CCL5 secreted by senescent thecainterstitial cells inhibits preantral follicular development via granulosa cellular apoptosis. J Cell Physiol. 2019; 234:22554-64.

https://doi.org/10.1002/jcp.28819 PMID:31111482

57. Liu Y, Pan J, Pan X, Wu L, Bian J, Lin Z, Xue M, Su T, Lai $S$, Chen F, Ge Q, Chen L, Ye S, et al. Klotho-mediated targeting of CCL2 suppresses the induction of colorectal cancer progression by stromal cell senescent microenvironments. Mol Oncol. 2019; 13:2460-75.

https://doi.org/10.1002/1878-0261.12577

PMID:31545552

58. Dabiri S, Kariminik A, Kennedy D. The role of CXCR3 and its ligands in renal transplant outcome. Eur Cytokine Netw. 2016; 27:34-40. https://doi.org/10.1684/ecn.2016.0375 PMID:27478077

59. Bhat H, Zaun G, Hamdan TA, Lang J, Adomati T, Schmitz $R$, Friedrich SK, Bergerhausen M, Cham LB, Li F, Ali M, Zhou F, Khairnar V, et al. Arenavirus Induced CCL5 Expression Causes NK Cell-Mediated Melanoma Regression. Front Immunol. 2020; 11:1849.

https://doi.org/10.3389/fimmu.2020.01849 PMID:32973762

60. Shou $\mathrm{Q}, \mathrm{Fu} \mathrm{H}$, Huang $\mathrm{X}$, Yang Y. PARP-1 controls NK cell recruitment to the site of viral infection. $\mathrm{JCl}$ Insight. 2019; 4:121291. https://doi.org/10.1172/ici.insight.121291 PMID:31217354

61. Shin WJ, Pachynski RK. Chemerin modulation of tumor growth: potential clinical applications in cancer. Discov Med. 2018; 26:31-7.

PMID:30265853

62. Rennier K, Shin WJ, Krug E, Virdi G, Pachynski RK. Chemerin Reactivates PTEN and Suppresses PD-L1 in Tumor Cells via Modulation of a Novel CMKLR1mediated Signaling Cascade. Clin Cancer Res. 2020; 26:5019-35.

https://doi.org/10.1158/1078-0432.CCR-19-4245 PMID:32605911

63. Demaria M, O'Leary MN, Chang J, Shao L, Liu S, Alimirah F, Koenig K, Le C, Mitin N, Deal AM, Alston S, Academia EC, Kilmarx $S$, et al. Cellular senescence promotes adverse effects of chemotherapy and cancer relapse. Cancer Discov. 2017; 7:165-76. https://doi.org/10.1158/2159-8290.CD-16-0241 PMID:27979832 


\section{SUPPLEMENTARY MATERIALS}

\section{Supplementary Figures}

A
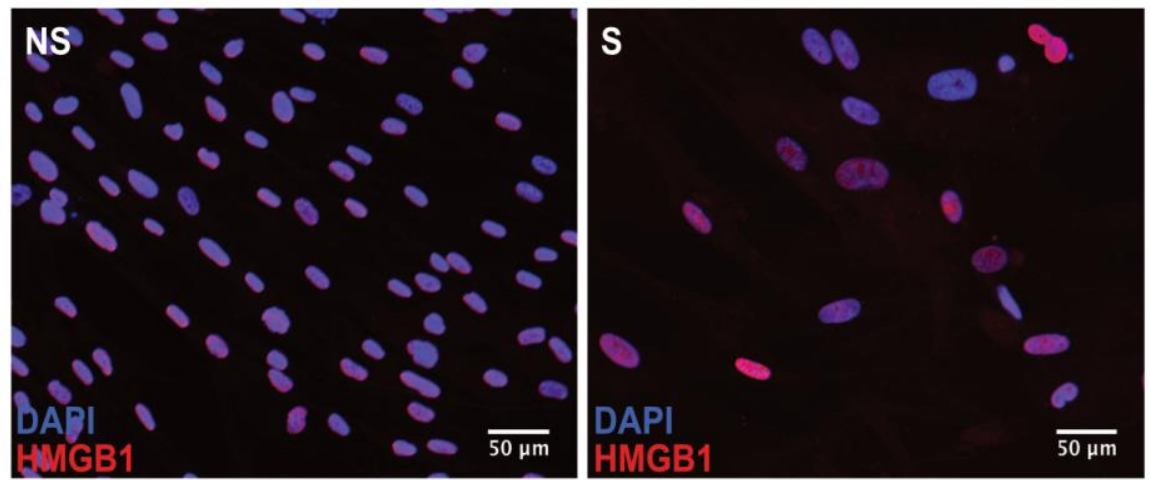

B
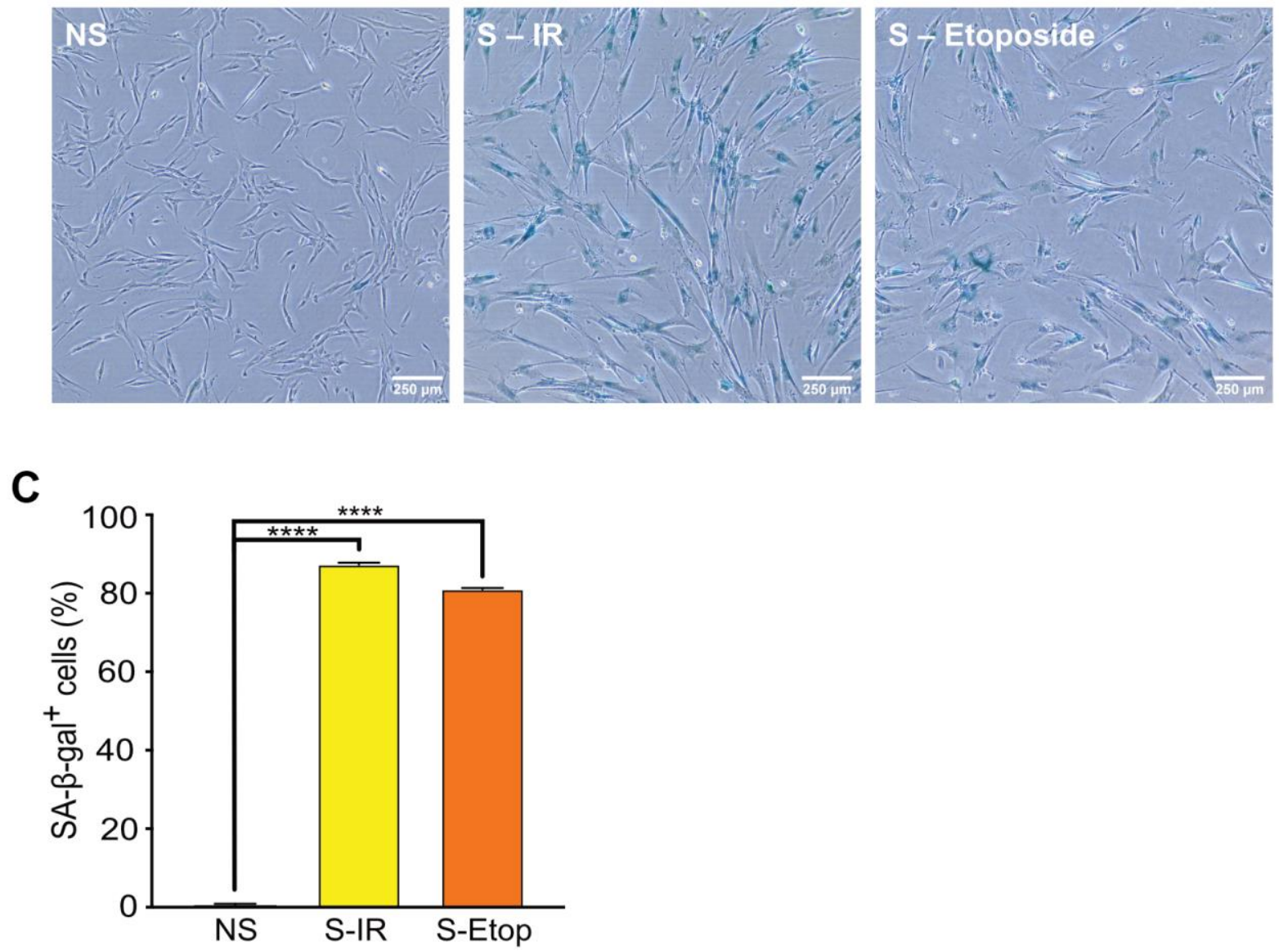

Supplementary Figure 1. Senescent IMR-90 cells express markers of senescence. Related to Figure 1. (A) Representative immunofluorescence images of NS and S IMR-90 cells stained for HMGB1 (red). Nuclei were stained with Hoechst (blue). (B) Representative images of SA- $\beta$-Gal-stained senescent (S - IR, $S$ - Etoposide) and non-senescent (NS) IMR-90 cells. SA- $\beta$-Gal staining was performed on day 9 after treatment with irradiation (20 Gy) or Etoposide $(20 \mu \mathrm{M}, 48 \mathrm{~h})$. (C) Quantification of SA- $\beta$-gal-positive IMR-90 cells in NS, S - IR and S Etoposide. Four fields were quantified per well $(n=3)$ with a total of 3483,1079 and 777 cells counted for NS, S - IR and S - Etoposide, respectively. 
A

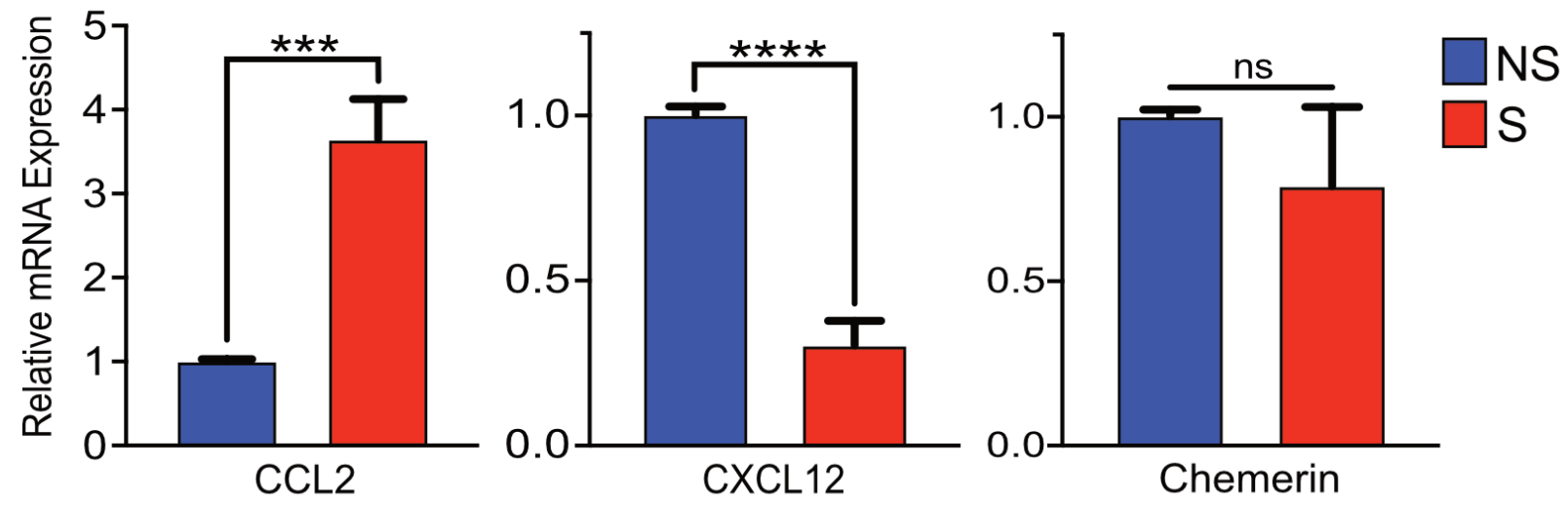

B

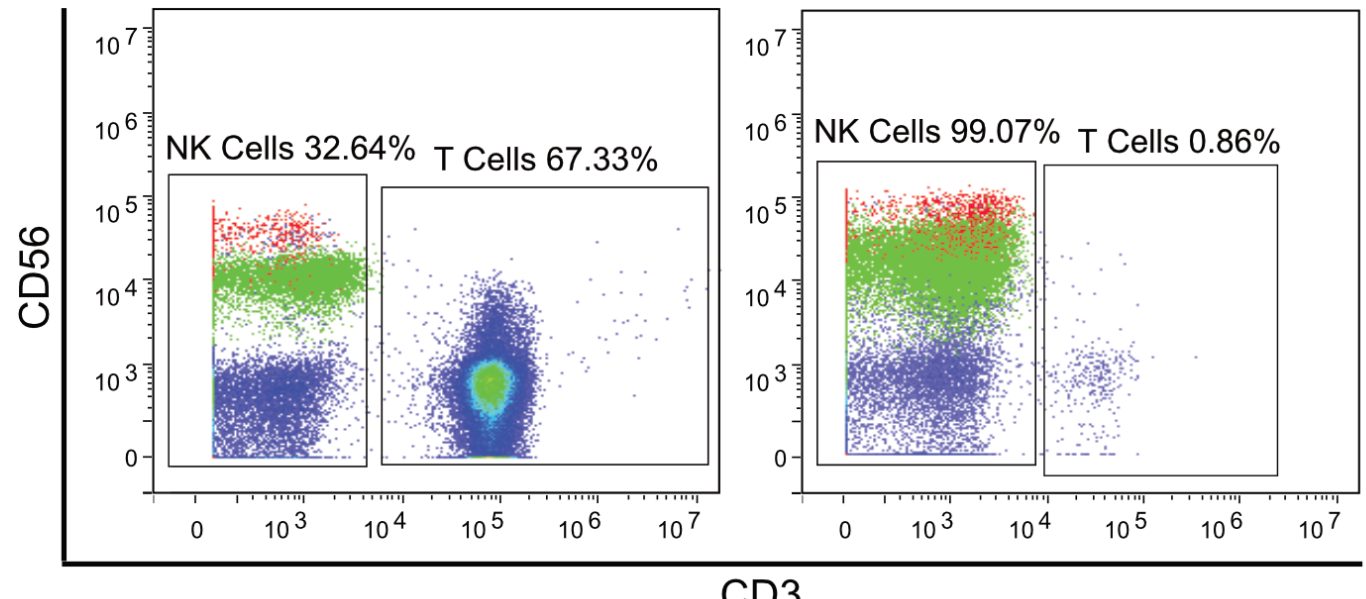

C-i

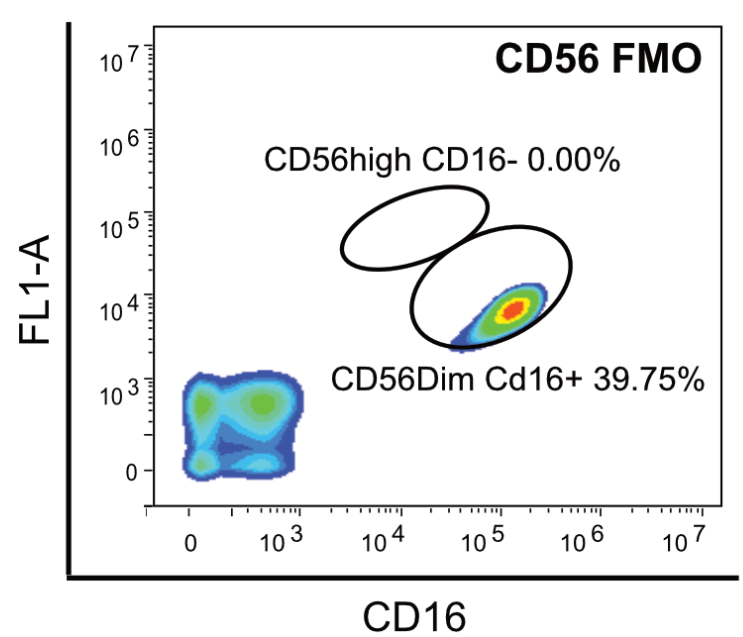

C-ii

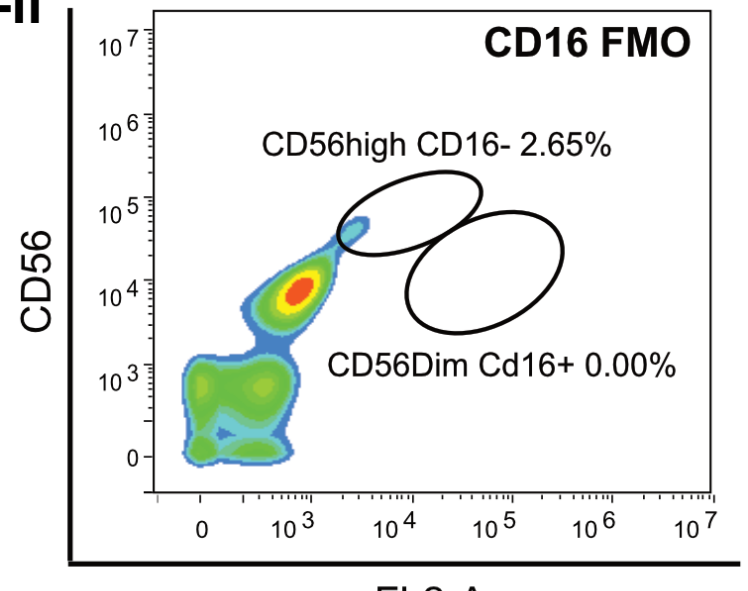

FL2-A

Supplementary Figure 2. Cytokine expression of non-senescent versus senescent IMR-90 cells and NK cell enrichment. (A) qRT-PCR of CCL2, CXCL12 and Chemerin mRNA in non-senescent and senescent IMR-90 fibroblasts. The results are presented as mean fold change in NS compared to $S$ of two independent experiments performed in triplicate, and error bars represent $\pm S E M$. Statistical analysis performed using unpaired t test. ${ }^{*} p<0.05,{ }^{*} p<0.01$, and ${ }^{* * *} p<0.001$. (B) Flow cytometry analysis of CD56 and CD3 expressing cells before (left) and after (right) enrichment. Rosette antibody-based isolation resulted in a pure population (99.07\%) of NK cells. Red is CD56 bright and green is CD56 dim NK cells. (C-i) Fluorescence Minus One (FMO) control for CD56 from a representative donor. NK cell populations were stained with anti-CD16 antibody. (C-ii) FMO control for CD16. NK cell populations were stained with anti-CD56 antibody. 
A
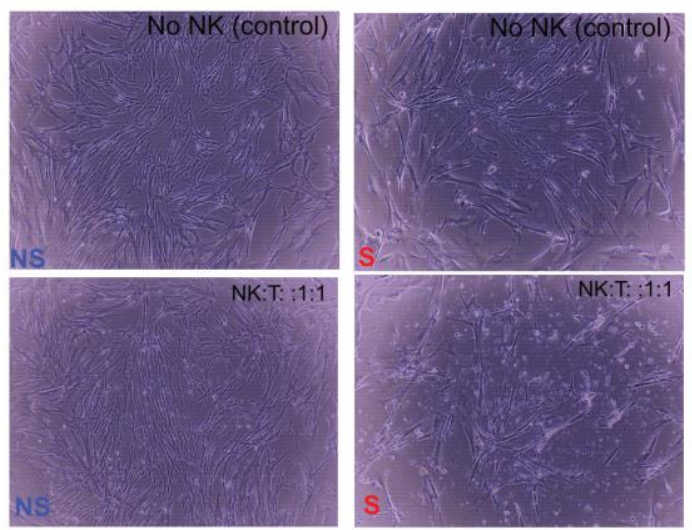

B

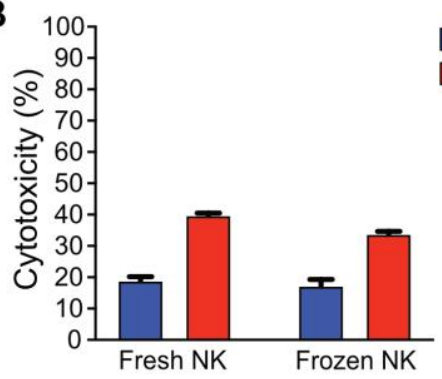

C
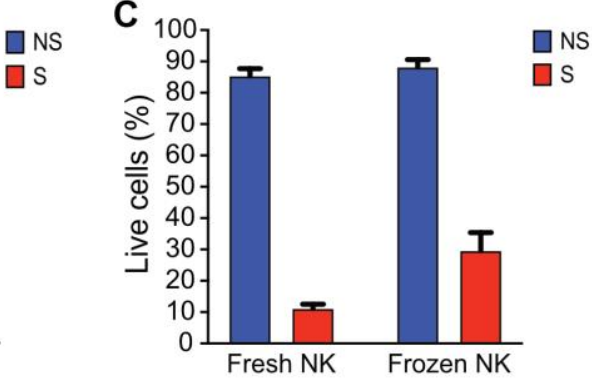

D-i

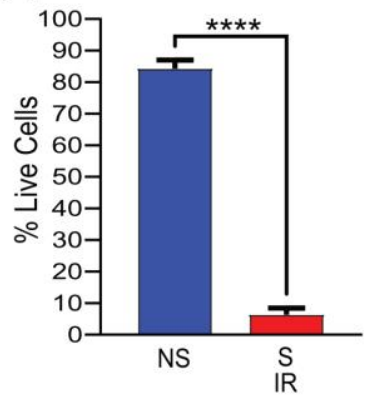

D-ii

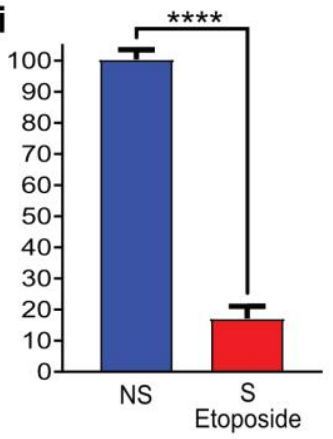

E

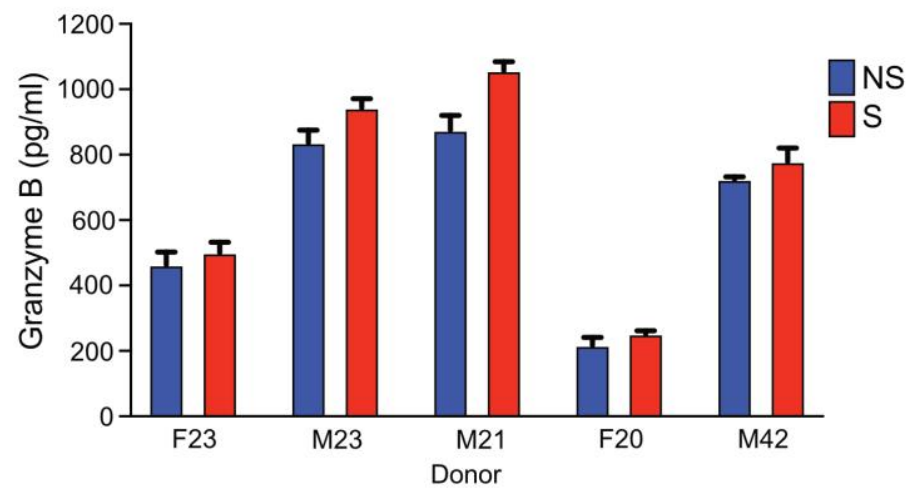

Supplementary Figure 3. Activated primary NK cells selectively eliminate senescent cells. Related to Figure 3. (A) Representative light microscopy images showing NK cell cytotoxicity towards NS versus S IMR-90 cells after $16 \mathrm{~h}$ of co-culture. (B) Cytotoxicity of NK cells that had been freshly isolated $3 \mathrm{~d}$ before co-culture ("fresh") versus NK cells that had been revived from storage in liquid nitrogen $3 \mathrm{~d}$ before coculture ("frozen") after $16 \mathrm{~h}$ of co-culture. Cytotoxicity was evaluated by LDH release. (C) Quantitative analysis of IMR-90 target cell viability after $4 \mathrm{~d}$ of co-culture with frozen or fresh NK cells, as measured by Calcein AM. (D-i) Percentage of live cells after $4 \mathrm{~d}$ of co-culture with NS cells or fibroblasts induced to senesce by irradiation (20 Gy) or (D-ii) etoposide (20 $\mu \mathrm{M}, 48 \mathrm{~h}$ ). (E) Granzyme B production of NK cells from 5 different donors in response to $16 \mathrm{~h}$ of incubation with NS or S IMR-90 cells. Donor sex and age are indicated in the figure. 